\title{
ARTICULAÇÃo ENTRE PRODUÇÃO E LOGÍSTICA NO FINAL DO SÉCULO XX E INÍCIO DO XXI: REFLEXOS NO ESTADO DE SÃO PAULO
}

\section{Linkage between production and logistics at the end of the twentieth century ante the beginning of XXI Century: reflections on the State of São Paulo (Brazil)}

\author{
Cássio Antunes Oliveira \\ Doutorando em Geografia, UNESP, Presidente Prudente-SP \\ cassio.antunes@gmail.com
}

Artigo recebido em 23/02/2012 e aprovado em 01/08/2012

RESUMO: A produção tem-se mostrado cada vez mais vinculada ao sistema logístico. Com a reestruturação produtiva é possível apontar transformações no sistema produtivo como: vinculação mais acentuada entre a produção e a distribuição, nas localizações das unidades industriais, comerciais e de serviços. Tais mudanças exigiram do Estado maiores investimentos nos sistemas de transportes e de comunicações que são imprescindíveis à logística, além de optarem pela privatização ou pelas concessões de rodovias e ferrovias. Por meio dessas afirmações o artigo tem a pretensão de mostrar como ocorreu e ocorrem estes processos utilizando-se de exemplos e manifestações desses acontecimentos no Estado de São Paulo.

Palavras-chave: Produção, logística, reestruturação produtiva, desconcentração industrial.

RESUMEN: La producción ha mostrado estar cada vez más vinculada al sistema logístico. Con la reestructuración de la producción es posible identificar transformaciones en el sistema productivo en los vínculos más fuertes entre la producción y la distribución, en las localizaciones de las unidades industriales, comerciales y de servicios, y por último, en la estructura de los empleos. Estos cambios han requerido grandes cantidades de inversión de los gobiernos en los sistemas de transporte y comunicaciones, que son la base logística, además de optar por la privatización o concesión de carreteras y ferrocarriles. A partir de estas afirmaciones el artículo pretende mostrar cómo ocurrió y ocurren estos procesos apoyándose en ejemplos de las manifestaciones de esos acontecimientos en el Estado de São Paulo.

Palabras clave: producción, logística, la reestructuración, la descentralización industrial. 


\section{INTRODUÇÃO}

A Segunda Guerra Mundial provocou mudanças de diferentes naturezas na maioria dos países, nas dimensões espacial, econômica, política e cultural. Partindo dessa premissa interessa, nesse texto, principalmente a dimensão econômica e a compreensão que dela decorre no que tange às transformações nos sistemas produtivos e organizativos das empresas e as espaciais e territoriais. A partir das décadas de 1950 e 1960 sucessivas crises econômicas contribuíram para que os empresários, principalmente os industriais, repensassem suas estratégias produtivas, competitivas (BALLOU, 2010) e de localização das unidades produtivas (MANZAGOL, 1985; SELINGARDI-SAMPAIO, 2009).

No período mencionado do início da segunda metade do século XX as empresas buscaram formas de se tornarem mais competitivas. Assim, as empresas se viram obrigadas a investir em setores como os de distribuição e abastecimento de mercadorias e de gestão de estoques em razão do acirramento da concorrência. Nesse mesmo período ocorreu a primeira crise do fordismo e, consequentemente, os primeiros indícios do regime de produção flexível, conforme já demonstrou Harvey (2003). Um pouco diferente do que se poderia supor, o regime de produção flexível exigiu muito mais eficiência na gestão de estoques do que exigira o fordismo. Se por um lado os estoques diminuíram com as novas formas de organização, por outro lado, aumentaram de modo significativo a variedade de produtos, e isto exigiu adaptações nas atividades de gestão. Certamente é muito mais difícil gerir um depósito com cem unidades iguais para quinhentos tipos diferentes de produtos do que cinco mil unidades iguais para cinco tipos diferentes de produtos.

Com estas informações iniciais mais ligadas à atividade de administração, acredita-se que se têm subsídios para que seja possível estabelecer relações entre o sistema da produção e um dos seus subsetores, o da distribuição de mercadorias o que inclui o transporte, a gestão de estoques e o processamento de pedidos de clientes. Nessa direção o objetivo desse texto é estabelecer uma análise em que sejam evidenciadas as relações entre a produção e a logística considerando as transformações engendradas pela emergência do regime de produção flexível e da reestruturação produtiva. Para tanto, tomar-se-á, como exemplo, em algumas partes do texto, a manifestação dessas relações e as transformações nas dinâmicas territoriais do Estado de São Paulo.

A produção será compreendida a partir das concepções de Marx (1982) registrada no livro "Para a crítica da economia política; salário preço e lucro; o rendimento e suas fontes: a economia vulgar". As considerações de Marx (1982) serão relativizadas, uma vez que se trata de escritos do século XIX (1859), e, evidentemente, o modo capitalista de produção e o sistema financeiro da atualidade se tornaram mais complexos, passados mais de cento e cinqüenta anos. A logística será abordada a partir das contribuições de Ballou (2010), que é considerado um dos primeiros autores a estudá-la de acordo com suas novas funções. Além de Ballou (2010), em relação à temática da logística, buscou-se também contribuições de Silva Junior (2009) e Silveira (2009).

\section{CONSIDERAÇÕES SOBRE A PRODUÇÃO}

A produção, de acordo com Marx (1982), se divide em três etapas principais: produção, distribuição e consumo (troca). A produção se refere à transformação de matérias-primas e outros objetos para que se tornem mais aptos aos diversos tipos de necessidades humanas. É possível exemplificar esta etapa com as atividades desenvolvidas nas unidades fabris. A distribuição é compreendida como as atividades de escoamento de produtos oriundos da produção, remetendo-se as mercadorias aos clientes e suprindo as necessidades de matéria-prima para as unidades produtivas. A distribuição atua, portanto, a montante e a jusante da etapa da produção. A logística contribui com a etapa da distribuição. Por último, no processo geral da produção há a etapa do consumo e da troca. Nesta etapa ocorre a comercialização e o uso das mercadorias e produtos que pode ser exemplificado pelas atividades de comércio e serviços. Há que se fazer uma ressalva, pois essa forma de se apresentar as três principais etapas do processo da produção é apenas uma maneira didática de traduzi-la ao leitor. $\mathrm{Na}$ verdade, Marx (1982) deixa bem claro que o processo 
da produção é cíclico, ou seja, o consumo é ao mesmo tempo consumo e produção, uma vez que ao se consumir um produto cria-se a necessidade de produção do mesmo produto. Para finalizar, é interessante que o leitor compreenda que as três principais etapas são interdependentes.

No Estado de São Paulo, são perceptíveis estas três etapas abordadas, conforme descritas por Marx (1982), ao se percorrer as rodovias que fazem parte dos eixos de desenvolvimento econômico no estado formados pelas rodovias Presidente Dutra (BR 116), Anhanguera (SP 330), Bandeirantes (SP 348) e Castelo Branco (SP 280). A partir de trabalhos de campo realizados em algumas rodovias no Estado de São Paulo presenciou-se a existência, proximidade e correlação das três etapas da produção ao se constatar expressivo número de unidades industriais, comerciais e de prestação de serviços localizadas próximas à rodovia, bem como concentradas nas áreas industriais dos municípios, como os distritos e condomínios empresariais. Outra evidência importante para é o fato de que o fluxo simultâneo de caminhões e carros nas rodovias mostrou-se bastante intenso, em parte significativa das rodovias que formam os eixos supracitados, o que indica a dinâmica nestes eixos, principalmente próximos as regiões metropolitanas de São Paulo, Campinas e de Santos, se pensar na logística para promover a realização geral do processo da produção. O trabalho de campo nesses eixos ocorreu em duas etapas em 2009.

O estudo e os trabalhos de campo nos eixos auxiliam a compreensão dos novos requisitos locacionais que após a reestruturação produtiva passaram a buscar ainda mais os locais com maiores possibilidades de fluidez territorial. Desta forma, é possível dizer que diferentemente da época em que Marx (1982) registrou suas impressões sobre o processo produtivo, na atualidade a etapa da distribuição passou por profundas transformações. Houve, de acordo com Ballou (2010), maior valorização da logística no processo produtivo, uma vez que os empresários perceberam que havia certa desagregação de atividades que deveriam ser gestadas conjuntamente. Esta valorização da logística refletiu em mudanças territoriais, como investimentos em infraestruturas de transportes e comunicações, relativa desconcentração industrial, e também a criação de normatizações para acelerar a circulação de mercadorias.

\section{A REESTRUTURAÇÃO PRODUTIVA E SEUS EFEITOS ESPACIAIS}

Para se compreender de maneira mais completa a vinculação acentuada entre o setor da produção com o da distribuição é essencial contextualizar a reestruturação produtiva. Esta reestruturação produtiva diz respeito ao conjunto de transformações pelas quais passou todo o processo da produção, sendo que este último termo é utilizado a partir das ponderações de Marx (1982), ou seja, a produção como um todo que inclui o setor produtivo, o distributivo e o do consumo e da troca. Em todas as etapas da produção foram observadas transformações.

Dall'Aqua (2003), que realizou estudo objetivando interpretar a competitividade e participação das cadeias produtivas na atualidade, apresenta a reestruturação produtiva como,

\section{[...] o conjunto das transformações na estrutu- ra produtivas das empresas e das sociedades em busca de modernizações e diminuição de custos. Estas mudanças são motivadas pelo crescimento significativo da velocidade das transformações tecnológicas, pela situação conjuntural internacional e pelo processo de globalização econômica (p. 33).}

Ballou (1993) fez apontamentos no início da década de 1990 que, posteriormente, foram confirmados por Dall'Aqua (2003). Para Ballou (2010) em razão do aumento da competividade nas décadas de 1950 e 1960 houve sucessivas pequenas crises econômicas, aumento da competitividade, etc., principalmente nos países que haviam sido reestruturados após terem sofrido perdas por conta da Segunda Guerra Mundial. Assim, foi necessário ações mais incisivas dos setores administrativos no sentido de apresentarem maiores rentabilidades para as empresas. Somado a isso, mas já na década de 1970, as crises do petróleo também reverberaram em mudanças em praticamente todos os setores do processo da produção. 
Na mesma linha de raciocínio, Selingardi-Sampaio (2009), entende que os fatores que engendraram a reestruturação produtiva estão ligados,

\section{[...] com a grave depressão econômica que se abateu sobre os países capitalistas, e os governos, principalmente dos países desenvol- vidos, [estes] foram compelidos a promover experiências de política econômica destinadas a superar a dificil situação de estoques de excedentes de produtos e de matérias-primas, escassez de créditos, baixos salários, alto desemprego, falta de demanda etc. (p. 141).}

De modo sucinto pode-se afirmar que todos os fatores elencados significaram, para os administradores de empresas e para os governos de diversos países, diminuição de seus lucros. Assim, medidas a serem tomadas eram imprescindíveis com o objetivo de resgatar o patamar de lucros dos " 25 anos gloriosos", em que os países avançados gozaram de crescimento econômico vertiginoso, conforme afirmou Moraes (2005). Tais medidas foram tomadas em todos os setores e subsetores do processo da produção, como exemplo pode-se apontar as mudanças nas relações de trabalho estudadas por Herédia (2004). Interessam mais nesse texto as transformações apresentadas em aspectos como o da localização de novas unidades produtivas e das mudanças no setor distributivo.

No setor administrativo de muitas empresas, principalmente no último quartel do século XX, passou-se a unir três etapas antes administradas de forma independentes (BALLOU, 2010). Por essas razões acredita-se que se no Brasil as evidências das escolhas das localizações de novas unidades industriais apontam que as condições logísticas, são hoje muito mais importantes do que foram até meados do século XX. Assim, localizar unidades produtivas próximas de locais em que as condições de fluidez sejam mais facilitadas não é o fato "novo", mas o que se pode apontar como realmente adicional às características do período anterior é a relevância que o setor logístico significou para a maioria das empresas que buscam competitividade.

Para que a compreensão da reestruturação produtiva seja mais clara, tomar-se-á como exemplo uma fábrica que antes das mudanças substanciais em suas etapas produtivas concentrava todas as etapas produtivas, ou seja, funcionava como uma unidade autônoma. Fischer (2008) atribui como um dos principais responsáveis pelas transformações espaciais a partir da década de 1970 a indústria de alta tecnologia. Para Fischer (2008),

\section{O rápido desenvolvimento das indústrias de alta tecnologia a partir dos anos setenta marca uma mudança radical em matéria de mobilidade espacial das atividades indus- triais. A multiplicação de pequenas unidades especializadas, a prática muito comum da disjunção funcional e da segmentação técnica que facilitam grandemente a divisão espacial do trabalho, a permanência das empresas de hoje em deslocalizar para espaços menos custosos as atividades mais banais ou mais padronizadas... (p. 26-27).}

Assim, com a reestruturação produtiva passou-se de uma realidade em que "a lógica externa dos fatores de localização associadas a lugares particulares é, hoje menos importante que a lógica de organização interna das empresas" (FISCHER, 2008, p. 27). Acrescenta-se aos fatores apontados pelo autor os avanços não apenas do desenvolvimento de tecnologia de ponta utilizada pelas empresas, mas também à nova forma da logística e às melhorias nos meios e nas infraestruturas de transportes. Até porque todos esses fatores estão interligados e, por conseguinte mudanças nas lógicas produtivas são engendradas e engendram mudanças nos sistemas de circulação.

Essas mudanças nos processos produtivos em razão da adoção das novas tecnologias, telemática e do papel mais relevante da logística, permitiram que houvesse a disjunção funcional. A disjunção funcional diz respeito ao fracionamento da unidade produtiva, o que pode deslocalizar processos que antes que necessitavam estar necessariamente próximos. Uma característica foi o aparecimento de muitas pequenas e médias empresas especializadas em partes específicas de um determinado produto, e também a separação entre as atividades que requerem mais incremento de Pesquisa e Desenvolvimento (P\&D), que comumente 
se localizam nas metrópoles e nos tecnopólos e as atividades banais que flexibilizaram suas localizações para áreas mais distantes das metrópoles (FISCHER, 2008).

Caiado (2002), que analisou a reestruturação produtiva e a localização industrial tomando como objeto para investigação a Região Metropolitana de São Paulo afirma que,

Setores industriais com reduzida competitividade, dificuldade de incorporação de inovação elou com elevada participação de exportações em suas vendas têm optado por se deslocar para (ou se instalar em) regiões periféricas. São exemplos as expansões da têxtil no CE, de couro e calçados no CE e $P B$, de alimentos e bebidas no AM, GO, MS e MT, de confecções em SC, PR, GO e MG. Movimento oposto é observado nos setores industriais tecnologicamente mais complexos elou voltados ao mercado de maior renda pessoal, com reconcentração em São Paulo e nos Estados vizinhos (p. 3).

Caiado (2002); Herédia (2004); Fischer (2008) e Silveira (2009) atribuem à inovação tecnológica e a terceira revolução industrial como processos que causaram transformações na esfera produtiva (CAIADO, 2002; HERÉDIA, 2004; FISCHER; 2008; SILVEIRA; 2009). Silveira (2009) e Ballou (2010) também destacam a relevância que a logística apresenta nesse contexto.

Outra perspectiva para se compreender a reestruturação produtiva é por meio do estudo da decadência (mas não extinção) do regime de acumulação fordista e da ascensão do regime flexível (BENKO, 1996; HARVEY, 2003; BOTELHO, 2000). Harvey (2003) delineia os principais elementos que evidenciam o novo regime de acumulação, o flexível, baseando-se em mudanças nas relações de trabalho, sociais, políticas e culturais.

Após 1966, de acordo com Harvey (2003), há queda da produtividade e lucratividade corporativas que gerou problema fiscal nos EUA. Estes acontecimentos coincidiram com uma época de políticas de substituição de importações em países de Terceiro
Mundo, e o primeiro grande movimento das multinacionais na direção da manufatura no estrangeiro (Sudeste Asiático), geraram industrialização fordista competitiva. No período entre 1965 e 1973 o fordismo e o keynesianismo foram incapazes de conter as contradições no capitalismo, tais como problemas de rigidez dos mercados (impediam muita flexibilidade de planejamento), rigidez de compromissos do Estado (programas de assistência aumentavam). O instrumento de resposta era a política monetária e esta desencadeou uma onda inflacionária. Produziu crise nos mercados imobiliários e severas dificuldades nas instituições financeiras. A OPEP aumenta no início da década de 1970 os preços do petróleo agravando ainda mais a crise do fordismo (HARVEY, 2003).

$\mathrm{Na}$ década de 1970 havia, principalmente nos países desenvolvidos, corporações com muita capacidade ociosa e isso redundou em um processo de racionalização, reestruturação e intensificação do controle do trabalho. As transformações tecnológicas, a busca por novas linhas de produtos, dispersões geográficas, fusões, são características da acumulação flexível (HARVEY, 2003).

Para relacionar a reestruturação produtiva com as ações dos agentes produtivos localizados no Estado de São Paulo é possível afirmar que com a abertura do mercado brasileiro à economia mundial, muitas indústrias brasileiras que se encontravam com seus sistemas organizacionais e de maquinaria ultrapassados frente ao que se praticava nas economias centrais foram prejudicadas em razão da perda de competividade de seus produtos no mercado. Este fato atingiu fortemente essas indústrias, que não estavam preparadas tecnicamente para competir com os produtos industriais importados. Muitas faliram, outras tiveram que se readequar investindo em novas tecnologias, marketing, pessoal treinado entre outras estratégias. Nesse processo observa-se que houve no Brasil flexibilização de muitas indústrias, principalmente, no Estado de São Paulo (CAIADO, 2002).

De acordo com Benko (1996, p. 236) flexibilidade deve ser "[...] entendido também como a possibilidade para empresas, de se subtrair a uma parte dos saques sociais e fiscais e, mais geralmente, de se libertar das regulamentações públicas que lhes limitam a liberdade de ação". Em seguida prossegue 
afirmando "que todos esses elementos mostram que um novo regime de acumulação e de modo de regulação emerge, criando novos espaços de produção ao reorganizar o sistema produtivo (de maneira flexível)".

A constituição dos eixos de desenvolvimento econômico em certo sentido relaciona-se ao que Benko (1996) compreende por flexibilidade, uma vez que na década de 1990 e no início do século, o espaço do Estado de São Paulo passou por mudanças significativas. Os eixos podem ser entendidos como espaços de concentração da produção e de pontecialização da acumulação de capital.

De acordo com Piquet (2007), evidências empíricas indicam as mudanças espaciais decorrentes da reestruturação contemporânea, tais como:

- As atividades produtivas, sobretudo as industriais, mudam seu padrão de localização;

- As regiões fortemente especializadas em ramos industriais tradicionais entram em colapso e passam a apresentar graves problemas de produtividade e obsolescência;

- As regiões metropolitanas como um todo perdem dinamismo demográfico, e, contrariamente, certas regiões que expulsavam população convertem-se em pontos de atração;

- O conjunto do sistema urbano-industrial dá mostras de mudanças em suas tendências de crescimento, em que se constata menor dinamismo nas zonas que abrigam as indústrias de maior porte do que nas que sediam empresas que operam com plantas menores.

- As grandes cidades passam a crescer em ritmo mais lento do que as localidades pequenas e os assentamentos rurais; e

- A lógica interna de produção e reprodução das aglomerações urbanas sofre mudanças significativas com a privatização dos serviços urbanos e sociais (PIQUET, 2007p. 89).

Todas essas evidencias apontadas por Piquet (2007), podem com maior ou menor intensidade, serem constatadas no Estado de São Paulo.

Para finalizar esta parte, resta ponderar que a partir de pesquisa bibliográfica na literatura que discute as mudanças nos processos produtivos contatou-se que muitos autores que compartilham a ideia de que essas transformações podem ser compreendidas por meio da reestruturação produtiva, conforme se percebe pela articulação de suas principais ideias nesse texto. No entanto, há que se registrar que para outros autores, o que se observa é que ocorreu um golpe estrutural no capitalismo que está em decadência. Os principais autores que defendem essa idéia são Katz e Coggiola (1997) e Braga (2003).

Além da reestruturação produtiva, que são ações mais voltadas à reorientação no processo da produção, houve também mudanças na dimensão política, o famigerado neoliberalismo, estudado por Fiori (1997), Petras (1999), Serra e Serra (s.d).

\section{LOGÍSTICA CORPORATIVA: SEUS EFEITOS E A LOCALIZAÇÃO INDUSTRIAL}

Conforme fora demonstrado, a partir da reestruturação produtiva a logística foi um dos setores que mais recebeu atenção nos setores administrativos das empresas. Os meios e as infraestruturas de transportes foram grandes responsáveis pelo aumento do comércio mundial na segunda metade do século XX. A revolução causada pela difusão do uso do contêiner, por exemplo, é emblemática, em função da possibilidade de se transportar uma variedade muito grande de produtos (unitizados) para longas distâncias e em diferentes meios de transporte como trem, caminhão e navio. Estas mudanças nos sistemas de transportes contaram com os avanços técnicos nos setores de comunicação e informática que, combinados, influenciaram nas escolhas para localização de unidades produtivas. Para Martins e Caixeta Filho (1998),

\section{[...] a integração de empresas para prestação de serviços intermodais, conjugada com uso intensivo de sistemas modernos de comu- nicação, tem sido um elemento norteador no objetivo primordial do atendimento dos requisitos do mercado consumidor, fazendo com que a eficiência do sistema logístico se torne uma condição básica de competitividade da economia (p. 81-82).}


Relacionado a essas mudanças provocadas pelos avanços nos setores distributivos, as empresas puderam flexibilizar a localização de suas unidades produtivas em locais mais distantes dos seus centros gestores e dos locais produtores de suas matérias-primas e de seus insumos produtivos. A desconcentração industrial de São Paulo foi possível, sobretudo em razão de melhorias que ocorreram nos sistemas de transportes. Contudo, deve-se destacar que a desconcentração industrial de São Paulo (ou crescimento industrial para o interior do estado), já discutida por autores como Lencioni (1994), Negri (1996), Caiado (2002) e Selingardi-Sampaio (2010), foi potencializada ainda por dois outros motivos: as deseconomias de aglomeração da Grande São Paulo e a possibilidade de sustentação das atividades industriais em áreas do interior que apresentavam, conforme Selingardi-Sampaio (2009),

\section{[...] os respectivos tamanhos funcional e popu- lacional; os consideráveis parques industriais preexistentes; as infra-estruturas urbana e logística então já instaladas, ou em processo de instalação, tais como distritos industriais, que proliferavam pelo interior, e a localização estratégica junto a rodovias modernas, então recém implantadas, elou aperfeiçoadas; um elenco relativamente diversificado de centrali- dades urbanas (principalmente a comercial); as políticas de atração implementadas etc. (p. 203).}

Assim, fica evidente que as condições logísticas são vistas como sendo de suma importância para a política de reduções de custos e de competitividade das empresas. Na atualidade, as condições logísticas chegam, em certos casos, a representar parte muita expressiva dos fatores responsáveis pelas escolhas de localização próxima ou ao lado de importantes rodovias do Estado de São Paulo. Foi isso o que constatou Finatti (2008) ao estudar o condomínio empresarial Techno Park Campinas, instalado às margens da rodovia Anhanguera - SP 330, no município de Campinas. Em pesquisa realizada com as empresas que estão instaladas dentro do referido condomínio, Finatti (2008) levantou a informação de que a maioria dos empresários optou pela localização no condomínio em razão da proximidade com a rodovia Anhanguera e outras duas rodovias e com São Paulo e Campinas. Em outro exemplo, a pesquisa realizada por Oliveira (2009) sobre os motivos que levaram os empresários a optarem por se instalar junto às rodovias, aeroportos $\mathrm{e}$ ferrovias identificou que as condições logísticas estão entre os principais motivos.

A pesquisa feita por Oliveira (2009) se pautou em levantamento das empresas (industriais, de comércio e de serviços), instaladas às margens ou próximas às rodovias Anhanguera - SP 330, Presidente DutraBR 116, Washington Luis - SP 310 e Castelo Branco - SP 280. Para exemplificar com outro caso, a seguir há uma informação sobre os motivos que contribuíram para que uma empresa do ramo de eletrônicos optasse por se localizar no município de Hortolândia:

A localização é estratégica. Hortolândia fica a apenas $20 \mathrm{~km}$ do aeroporto internacional de Viracopos e concentra centros de pesquisa de excelência, como a Unicamp. Outras grandes empresas, como a IBM, têm bases instaladas na região. 'Setenta por cento dos negócios da Dell estão concentrados na região Sudeste. A questão da logística foi a mais importante na hora de escolher o lugar em que a fábrica seria construida', diz Raymundo Peixoto, diretor-geral da Dell no Brasil. (FERRARI, 2009).

Apesar de os municípios atravessados pelas rodovias supracitadas serem boas opções para a instalação de unidades industriais, comerciais ou de serviços, por conta do adensamento e da eficiência do sistema de circulação, há alguns empecilhos para os municípios citados e muito mais para o restante do Estado de São Paulo.

Silveira (2009) faz uma análise minuciosa das quatro revoluções logísticas apresentadas por Anderson (1990), e argumenta a possibilidade de se estar em curso uma quinta revolução. De acordo com o autor as revoluções logísticas ocorrem em razão de,

[...] mobilidade populacional (busca de trabalho, alimento, terras férteis, aventura e outros), quanto o comércio (local, regional ou 
internacional), as trocas simples (escambo) $e$ a conquista de territórios são fundamentais para entendermos os motivos das revoluções e inovações da logística (SILVEIRA, 2009, p. 14).

Com essa compreensão de revolução logística a quinta revolução logística seria caracterizada por maior integração comercial, infovias, auto-estradas, telemática, trens de alta velocidade (TAV), fibra ótica, comunicação via satélite, etc. Partindo desse contexto da quinta revolução logística é possível perceber que o Estado de São Paulo se adequa aos novos requisitos para que ocorra a eficiência logística. Assim, é possível apontar que o Estado de São Paulo continua com amplo potencial atrativo para os empresários, sejam industriais, do setor de serviços ou comercial.

\section{EMPECILHOS PARA A EFICIÊNCIA LOGÍS- TICA NO ESTADO DE SÃO PAULO}

É sabido que os gastos com transportes são preocupações do empresariado, pois este é mais um setor em que se pode buscar diminuição dos custos, daí a importância do papel dos operadores logísticos. No entanto, é pertinente ponderar que a afirmação anterior só é válida em países ou estado que possuem desigualdades regionais quanto à densidade e qualidade das infraestruturas de transportes, uma vez que se um país ou estado gozasse dos objetos técnicos e aparatos normativos homogêneos em todo seu território, o papel da logística não seria uma preocupação. Partindo dessas considerações, é possível dizer que no Brasil, e mais especificamente do Estado de São Paulo, as rodovias exercem papel muito relevante para a logística. No entanto, esse peso exercido pelas rodovias precisa urgentemente ser modificada, uma vez que, para que a etapa da distribuição seja mais eficiente, no Estado de São Paulo é necessário promover alterações na matriz de transportes e no sistema normativo para que as mercadorias cheguem aos seus destinos com mais rapidez e segurança.

De acordo com Silva Junior (2009), os Operadores de Transporte Multimodal (OTM) são capacitados para cumprir contratos de entrega de produtos com rapidez e eficiência. Há diferenças entre os OTM e as empresas transportadoras comuns, sendo que a principal delas é o fato de os OTM utilizarem, quando necessário, mais de um tipo de modal de transporte para realizar a entrega de mercadorias. $\mathrm{O}$ advento da regularização dos OTM, no que diz respeito às questões fiscais e tributárias se traduz em mais segurança e rapidez para os usuários de serviços logísticos. $\mathrm{O}$ ponto negativo da regularização e do aumento do número de OTM no Brasil é que tal crescimento poderá acarretar falências das pequenas empresas transportadoras que deixarão de ser competitivas (SILVA JUNIOR, 2009). Enfim, a vinculação mais acentuada, na atualidade, entre as etapas da produção, distribuição e troca (consumo) visando aumentar a velocidade de circulação do capital, tem consequências sobre a estrutura de empregos e sobre o uso corporativo do território.

Todas as afirmações feitas sobre a organização das atividades de distribuição em que se aponta o papel importante que a logística significou para as empresas devem ser compreendidas levando-se em consideração que não são todas as empresas que conseguem atuar no território utilizando das vantagens competitivas da logística. Há, conforme já alertaram Castillo (2004), Braga (2007), Silveira (2009) e Silva Junior (2009), um uso corporativo do território e dos ativos de circulação. Além do mais, as verdadeiras beneficiárias dos avanços dos sistemas de comunicações e logísticos são as grandes corporações e as grandes empresas, especialmente as que operam em vários países. A busca cada vez mais desenfreada pela rapidez na circulação do capital contamina o Estado, nas três esferas de poder, a dotar o território de condições propícias para a operação das mais diferentes atividades empresariais. Assim "[...] a utilização seletiva da logística, dos sistemas de movimento (infraestruturas e meios de transportes), das comunicações e das tecnologias da informação para a "energização" da circulação do capital" (SILVEIRA, 2009, p. 1) influencia tais ações do Estado.

Desta forma, é admissível fazer relações entre o empenho que o Estado apresenta ao realizar investimentos em obras que beneficiam muito mais a manutenção e a expansão das atividades de reprodução do capital do que em obras que beneficiam de forma direta os $34 \%$ da população brasileira que 
vivia em 2002 " [...] com uma renda insuficiente para atender às suas necessidades básicas de alimentação, vestuário, habitação e transporte" (FURTADO, 2002, p.11). Estão sendo investidos bilhões de reais em obras para sediar a copa do mundo de futebol de 2014 ou no Rodoanel que beneficiará, sobretudo, as grandes corporações, principalmente aquelas instaladas no Estado de São Paulo. Lembrando que partes significativas dos investimentos feitos para a copa do mundo são em transportes, com o intuito de melhorar a circulação de passageiros no território nacional, com a ressalva de que tais melhorias ocorrerão de forma quase total nas cidades que sediarão os jogos.

\section{CONSIDERAÇÕES FINAIS}

Conforme Ballou (2010, p. 18) "As atividades de transporte, estoques e comunicações iniciaram-se antes mesmo da existência de um comércio ativo entre regiões vizinhas". Na atualidade, o que se identifica como alteração é a forma em que a logística passou a ser valorizada e administrada pelas empresas. Assim, demandaram-se mais investimentos nos sistemas de transportes objetivando refletir em menor custo na movimentação de mercadorias e aumento da velocidade no transporte. Muito embora o fim principal a ser alcançado fosse, de modo geral, a mais rápida circulação do capital.

Em suma, é possível afirmar que há vinculação mais acentuada entre a produção (entendida nesse caso como uma das etapas do processo produtivo) e a logística (que se pode relacionar com a etapa da distribuição), por conta das transformações provocadas pela reestruturação produtiva. Assim, para o setor administrativo das empresas as demandas surgidas e a necessidade de redução de custos promoveram integração de setores antes divididos na empresa num único setor, o da logística, ou a delegação dessa atividade a empresas especializadas nessa atividade. Outra alteração identificada por conta da busca de maior rapidez na circulação do capital foram as estratégias de localização industrial que se expressaram pela maior articulação das rodovias mais atrativas à localização de unidades produtivas, comerciais ou de serviços no Estado de São Paulo.
As transformações provocadas pela reestruturação produtiva e pela relevância do papel da logística para as empresas também alteram as configurações espaciais e territoriais além de impactar a estrutura de emprego. O Estado foi "pressionado" a realizar grandes investimentos no sentido de melhorar a fluidez territorial, uma vez que isto passou a ser um requisito eficiente para atrair investimentos. Como conseqüência a parte da população mais necessitada continua aguardando que suas demandas mais imediatas se tornem prioridades nos programas de governo.

\section{REFERÊNCIAS}

BALLOU, R. H. Logística empresarial: transportes, administração de materiais, distribuição física. São Paulo: Atlas, 2010. 388p.

BENKO, G. Economia, espaço e globalização na aurora do século XXI. São Paulo: Hucitec, 1996. 264p.

BOTELHO, A. Do fordismo a acumulação flexível: a produção do espaço num contexto de mudança das estratégias de acumulação de capital. 148f. Dissertação (Mestrado em Geografia). São Paulo: FFLCH-USP, 2000.

BRAGA, R. A nostalgia do fordismo: modernização e crise na teoria da sociedade salarial. São Paulo: Xamã, 2003. 246p.

BRAGA, V. O PDDT e a fluidez territorial no Estado de São Paulo: o projeto dos Centros Logísticos Integrados. 133f. Dissertação (Mestrado em Geografia). Campinas: DG-IG-UNICAMP, 2007.

CAIADO, A. S. C. Desconcentração industrial regional no Brasil (1985 - 1998): pausa ou retrocesso. 269f. Tese (Doutorado em Economia). Campinas: IE/ UNICAMP, 2002.

CASTILLO, Ricardo. Transporte e logística de granéis sólidos agrícolas: componentes estruturais do novo sistema de movimentos do território brasileiro. Investigaciones Geográficas. Ciudad del Mexico, n. 55, pp. 79-96, 2004. 
DALL'ACQUA, C. T. B. Competitividade e participação: cadeias produtivas e a definição dos espaços geoeconômico global e local. São Paulo: Annablume, 2003. 176p.

FERRARI, B. Dell inaugura fábrica em Hortolândia.. Plantão Info. Disponível em: <http://info.abril. com.br/aberto/infonews/052007/14052007-19.shl>. Acesso em: 9 jul. 2009.

FINATTI, R. Reestruturação produtiva e produção do espaço urbano: a inserção interescalar do condomínio empresarial Techno Park Campinas. 142f. Monografia (Geografia). Presidente Prudente: FCT/ UNESP, 2008.

FISCHER, A. Os efeitos geográficos das novas tecnologias: abordagem geral. In. FIRKOWSKI, O. L. C. de F.; SPOSITO, E. S. (org.). Indústria, ordenamento do território e transportes: a contribuição de André Fischer. São Paulo: Expressão Popular, 2008. 160p.

FURTADO, C. Em busca de novo modelo: reflexões sobre a crise contemporânea. São Paulo: Paz e Terra, 2002. 101 p.

HARVEY, D. Produção capitalista do espaço. São Paulo: Annablume, 2006. 2a . ed. 251p.

HERÉDIA, V. Novas tecnologias nos processos de trabalho: efeitos da reestruturação produtiva. Scripta Nova. Revista electrónica de geografía y ciencias sociales. Barcelona: Universidad de Barcelona, 1 de agosto de 2004, vol. VIII, núm. 170 (9). Disponível em: <http://www.ub.es/geocrit/sn/sn-170-9.htm >. Acesso em: 25 out. 2009.

KATZ, C; COGGIOLA, O. Neoliberalismo ou crise do capital?. São Paulo: Xamã, 1997. 268p.

MANZAGOL, C. Lógica do espaço industrial. São Paulo: Difel, 1985. 230p.

MARTINS, R. S; CAIXETA FILHO, J. V. O desenvolvimento dos sistemas de transporte: auge, abandono e reativação recente das ferrovias. Revista Teor. Evid. Econ. V.6, n. 11, p. 69-91, nov. 1998.

MARX, K. Para a crítica da economia política; salário preço e lucro; o rendimento e suas fontes: a economia vulgar. São Paulo: Abril Cultural, 1982. (Coleção "Os economistas").

MORAES, R. C. C. de. Estado, desenvolvimento e globalização. São Paulo: Editora UNESP, 2006. 200 p.

NEGRI, B. Concentração e desconcentração industrial em São Paulo (1880 - 1990). Campinas: Unicamp, 1996. 242p.

OLIVEIRA, C. A. de. Eixos de desenvolvimento e concessões rodoviárias no Estado de São Paulo. Monografia (Geografia). Presidente Prudente, FCT/ UNESP, 2009. 97p.

PETRAS, J. Neoliberalismo: América Latina, Estados Unidos e Europa. Blumenau: Editora da FURB, 1999. 433p.

PIQUET, R. Indústria e território no Brasil contemporâneo. Rio de Janeiro, Garamond Universitária, 2007. 167 p.

SELINGARDI-SAMPAIO, S. Indústria e território em São Paulo: a estruturação do Multicomplexo Territorial Industrial Paulista: 1950-2005. Campinas: Alínea, 2009. 480p.

SERRA, C. H. A.; SERRA, M. A. Neoliberalismo, políticas sociais e exclusão social no Brasil. III Congresso Brasileiro de História Econômica. Anais...,1999 .

SILVA JUNIOR, R. F. da. Circulação e logística territorial: a instância do espaço e a circulação corporativa. Tese (doutorado em Geografia). Presidente Prudente: FCT/UNESP, 2009. 357p.

SILVEIRA, M. R. As cinco revoluções e evoluções logísticas e seus impactos sobre o território brasileiro. In: SILVEIRA, M. R.; LAMOSO, L. P.; 
MOURÃO, P. F. C. Questões nacionais e regionais do território brasileiro. São Paulo: Expressão Popular, 2009. p. 13-42.

SILVEIRA, M. R. Logística, sistemas de movimento, fluxos econômicos e interações espaciais no território paulista: uma abordagem para a Geografia dos Transportes e Circulação. Scripta Nova. Revista Electrónica de Geografía y Ciencias sociales. Barcelona: Universidad de Barcelona, 1 de febrero de 2009, vol. XIII, núm. 283<http://www.ub.es/geocrit/ sn/sn-283.htm>. 